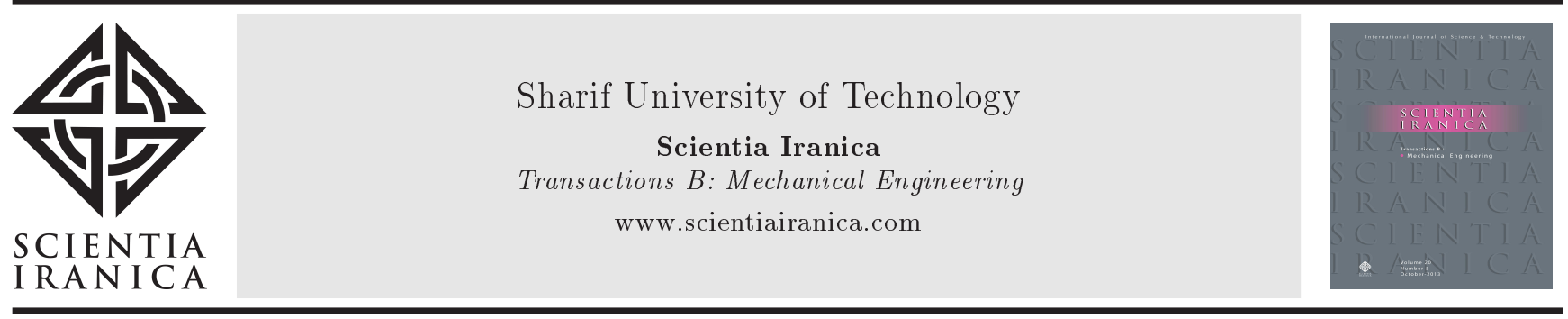

\title{
Simultaneous optimization of joint edge geometry and process parameters in gas metal arc welding using integrated ANN-PSO approach
}

\author{
M. Azadi Moghaddam*, R. Golmezerji and F. Kolahan \\ Department of Mechanical Engineering, Ferdowsi University of Mashhad, Mashhad, P.O. Box 917r5-1111, Iran.
}

Received 23 July 2015; received in revised form 25 January 2016; accepted 18 July 2016

\author{
KEYWORDS \\ Gas Metal Arc \\ Welding (GMAW); \\ Joint edge geometry; \\ Heat-Affected Zone \\ (HAZ); \\ Multi-criteria \\ optimization; \\ Artificial Neural \\ Network (ANN); \\ Particle Swarm \\ Optimization (PSO) \\ algorithm.
}

\begin{abstract}
Gas Metal Arc Welding (GMAW) is one of the most extensively used processes in automated welding due to its high productivity. However, to simultaneously achieve several conflicting objectives such as reducing production time, increasing product quality, full penetration, proper joint edge geometry, and optimal selection of process parameters, a multi-criteria optimization procedure must be used. The aim of this research is to develop a multi-criteria modeling and optimization procedure for GMAW process. To simultaneously predict Weld Bead Geometry (WBG) characteristics and Heat-Affected Zone (HAZ), a Back Propagation Neural Network (BPNN) has been proposed. The experimentally derived data sets are used in training and testing of the network. Results demonstrate that the finely tuned BPNN model can closely simulate actual GMAW process with less than $1 \%$ error. Next, to simultaneously optimize process characteristics, the BPNN model is inserted into a Particle Swarm Optimization (PSO) algorithm. The proposed technique determines a set of values for parameters and the workpiece groove angle in such a way that a pre-specified WBG is achieved while the HAZ of the weld joint is minimized. Optimal results are verified through additional experiments.
\end{abstract}

(C) 2017 Sharif University of Technology. All rights reserved.

\section{Introduction}

Gas Metal Arc Welding (GMAW) is the most widely used process in automated welding industry. Because of its consumable electrode, GMAW has a higher productivity than another generally used arc welding process, i.e. Gas Tungsten Arc Welding (GTAW) [1]. High productivity rate due to the continuous feed of wire electrode, low weld discontinuity, no slag inclusion, and low thermal hazard on base metal is the main merit of this process [2].

Increasing productivity of any welding process while maintaining or even improving the weld quality

*. Corresponding author. Fax: +98-5138763304 E-mail address: masoudazadi888@gmail.com (M. Azadi Moghaddam) has been the task of scholars in development of welding processes [2]. Previous predictive studies on GMAW process have had various purposes. Researchers have attempted to model GMAW process and then tried to optimize it through different methods [3,4].

Different factors influence the size of HeatAffected Zone (HAZ) and Weld Bead Geometry (WBG), which have been considered as the most important measures in GMAW process. A significant group consists the process parameters to be set on the welding machine; viz., welding speed $(S)$, arc voltage $(V)$, wire feed rate $(F)$, and nozzle-to-plate distance $(D)$ [5]. Besides, in all fusion welding processes, selection of groove angle $(A)$ is a key variable affecting welding geometry. Without proper groove angle, the entire internal portion of the joint would not be fused, ending in a weak joint. Therefore, appropriate selection 
of groove angle, as well as the values of GMAW input parameters, plays an important role in determining the quality of the weld joint. Consequently, to achieve full penetrated weld with desired WBG, process parameters selection and joint edge preparation must be carefully considered.

Artificial Neural Networks (ANNs) are widely proposed in the literature as mathematical tools to implement the estimation methods needed in processes of this kind, because of its learning capability [5-8]. There are many types of ANNs, which vary in architecture, strategy of learning, and implementation of transfer functions. Back Propagation Neural Network (BPNN) has received considerable attention in view of its universal approximation capabilities. The main architectural features of BPNN are the number of hidden layers and the number of processing elements (nodes) in each hidden layer. These factors have to be taken into account and determined in advance of the process modeling [7-9].

From the literature review, Singh et al [9] studied the effect of polarity on WBG in Submerged Arc Welding (SAW) using mathematical models. Response Surface Methodology (RSM) has been used for predicting the critical dimension of WBG and shape relationships at straight polarity and reverse polarity. The developed models have been checked for adequacy and significance by F-test and t-test. The WBG and penetration in GMAW process have been modeled using ANN by Nagesh and Datta [10]. It has been shown that welding current, arc voltage, and welding speed are the parameters that mostly affect depth of penetration. Longer arc-length and too small arc-length produce poor penetration. It was shown that high arc travel rate or low arc power resulted in poor fusion. Higher electrode feed rate produced higher bead width. An ANN model for modeling and prediction of WBG in GMAW process with alternating shielding gases has been proposed by Campbell et al. [11]. The models were used to predict penetration, width, and effective throat thickness under a set of weld parameters and alternate frequency of shielding gas. A procedure based on ANNs for modelling of GMAW parameters has been proposed by Ates [12]. Mechanical properties of the weld joint such as tensile strength, impact strength, elongation, and weld metal hardness have been modeled and predicted using the proposed ANN. Results validated that ANN could be used as an alternative method to calculate the gas mixture.

Recently, various mathematical methods and heuristic algorithms have also been used to find the optimal process parameters settings. Heuristic algorithms such as Particle Swarm Optimization (PSO), Simulated Annealing (SA), ant colony, etc. have proved to be powerful methods for solving large combinatorial modeling and optimization problems such as multi-criteria optimization of manufacturing processes. An approach for modeling and optimization of GMAW process using regression modeling and $\mathrm{SA}$ algorithm has been presented by Kolahan and Heidari [13]. To develop mathematical models, different regression functions have been fitted on the experimental data gathered by orthogonal array technique. Next, SA algorithm has been used to develop the models. Confirmation results demonstrated that the proposed regression-SA method could accurately determine welding parameters as a desired bead geometry specification. To develop mathematical models for WBG of Tungsten Inert Gas (TIG) welding process, multiple linear regression techniques have been used [14]. Also, by using the same experimental data, an attempt has been made to model the process using BPNN. Then, Genetic Algorithmic (GA) coupled with BPNN has been applied to optimize the process parameters. The input-output relationships for flux cored arc welding of the mild steel plates were simulated by Dhas and Kumanan [15] through regression modeling technique. The developed model has been implanted into a PSO algorithm to determine optimal process parameters for minimization of BW. A good agreement between the optimized values obtained from this technique and experimental results has been shown. An ANN-PSO algorithm for simulation and optimization of WBG of $316 \mathrm{~L}$ nickel based super alloys in flux cored arc welding process has been proposed by Katherasan et al. [16]. ANN has been used for modeling of the process; then, the developed model has been embedded into a PSO algorithm, which optimizes the process parameters. Performances of regression analysis approach, BPNN, and ANN models coupled with GA (ANN-GA) have been compared for TIG welding process [17]. It has been illustrated that ANN approaches could produce predictions that are more adaptive than those of the conventional regression analysis approach. ANNs, GA, SA, and Quasi Newton line search techniques have been combined by Chaki et al. [18] to develop three integrated models of ANNGA, ANN-SA, and ANN-Quasi Newton for modelling and optimization of welding strength for hybrid $\mathrm{CO}_{2}$ laser-MIG welded joints of aluminum alloy. According to the results, integrated ANN-GA procedure has revealed the best performance in comparison with others.

According to the literature review, there is extensive research on modeling and optimization of GMAW process. Nevertheless, to the best of our knowledge, there is no published study in which both process parameters and groove angle are simultaneously considered and optimized using the proposed procedure. Therefore, in this study, a BPNN model has been developed to establish the relations between input and output parameters of the process. The proposed BPNN model has five input parameters and four 
output characteristics, among which we have taken into account the WBG as well as HAZ specifications. In the proposed BPNN-PSO approach, multi-criteria optimization is carried out to determine optimal groove angle and the values of process parameters simultaneously to obtain the desired WBG and minimum HAZ.

\section{Material and experimental procedure}

\subsection{Material and equipment}

Experiments were carried out on API-X42 steel plates, widely used in oil pipeline industry with dimensions of $120 \mathrm{~mm} \times 50 \mathrm{~mm} \times 10 \mathrm{~mm}$. The chemical composition and mechanical properties of the alloy are reported in Table 1.

API-X42 steel alloy is widely used in such industries in which the welded parts are subjected to high stresses or corrosive environments that demand high quality weld joints, such as petrochemical plants and oil pipelines. In these welding processes, the values of process parameters affect the quality of welded joints. Furthermore, for plates with more than $6 \mathrm{~mm}$ of thickness, joint edge preparation is often necessary when plates are to be welded. This edge modification concentrates heat in the area to be melted and allows for the reduction in the arc power necessary for penetration. The joint edge geometry is shown in Figure 1.

A GAAM-PARS MIG-SP 501W (GAAM-Co, Iran) semi-automatic welding machine with constant voltage and rectifier type power source has been used to carry out the experiments (Figure 2). A copper-

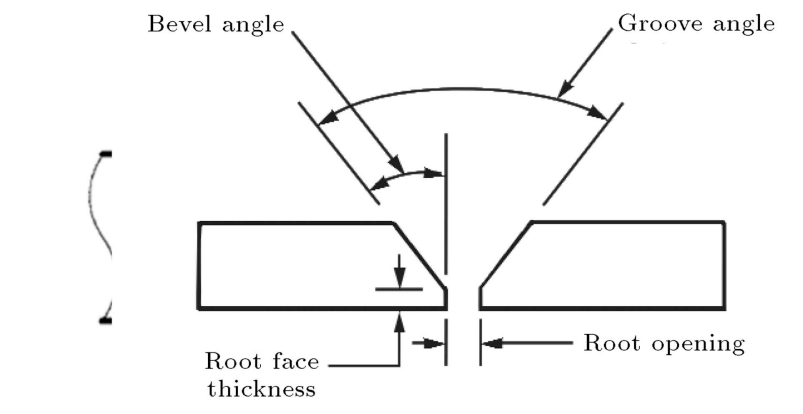

Heat A

Figure 1. Joint edge geometry for GMAW of plates with more than $6 \mathrm{~mm}$ of thickness. coated coil with $1 \mathrm{~mm}$ of diameter (ER70S-6G4Si1) has been used as electrode. A mixture of $75 \% \mathrm{Ar}$ and $25 \% \mathrm{CO}_{2}$, with the flow rate of $12 \mathrm{~L} / \mathrm{min}$, has been used as welding shield gas. A schematic illustration of GMAW process has been shown in Figure 2.

In this study, WBG for the specimens has been prepared by milling process in the form of $\mathrm{V}$-beveled based on ANSI/AWS D 1.1 standard [19].

\subsection{Design of experiments and experimental results}

Arc voltage is the electrical potential between the electrode and the workpiece before beginning the arc. This factor is a major factor that affects the energy input of arc and can be directly adjusted at the power supply; but, when the arc starts, arc voltage drops during the process. The nozzle-to-plate distance (the arc length) changes the arc voltage; therefore, increasing or decreasing the nozzle-to-plate distance will increase or decrease the arc voltage and arc length; but, by increasing the work length, the arc will be dispersed and this decreases the energy focus. Another important factor in GMAW is wire feed rate that controls the deposition rate. In constant-voltage rectifier-type GMA machines, the wire feed speed with arc voltage setting controls the amperage (an increase in wire feed speed and arc voltage increases the amperage while

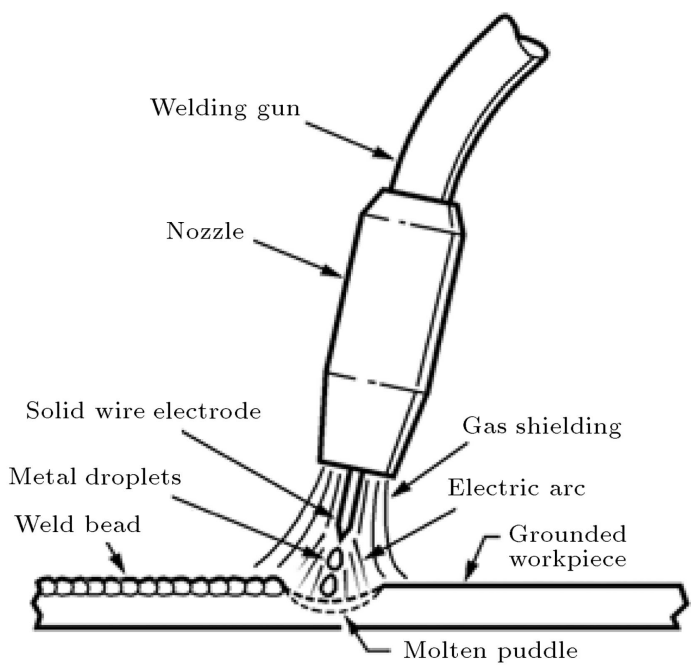

Figure 2. Schematic representation of the GMAW process.

Table 1. Chemical composition and mechanical properties of API-X42 steel alloy.

\begin{tabular}{lclc}
\hline \multicolumn{1}{c}{ Chemical composition } & Percentage (\%) & \multicolumn{2}{c}{ Mechanical properties } \\
\hline $\mathrm{Fe}$ & 97.25 & Yield Stress (YS) & $486 \mathrm{MPa}$ \\
$\mathrm{C}$ & 0.60 & Ultimate Tensile Strength (UTS) & $513 \mathrm{MPa}$ \\
$\mathrm{Mn}$ & 1.20 & YS/UTS & 0.95 \\
$\mathrm{Si}$ & 0.45 & Fracture energy in $30^{\circ} \mathrm{C}$ & $117 \mathrm{Joule}$ \\
Other elements: $\mathrm{Si}+\mathrm{Mg}+\mathrm{Cr}+\mathrm{Ti}$ & 0.50 & Total elongation & $21 \%$ \\
\hline
\end{tabular}


welding and vice versa) [1]. Therefore, on GAAMPARS MIG-SP 501W machine, the welding current is not an independent factor and welding amperage is a function of the feed rate and voltage. An increase or decrease in welding speed (nozzle travel speed) causes higher or lower filler metal to be deposited on the base metal. The travel speed must be increased to maintain the reasonable process efficiency and lower time of production process; however, incomplete fusion may occur on fast nozzle traverse speed. With excessive travel speed, the arc will outpace the shielding gas, resulting in porosity. To obtain a quality weld and cost-effective use of filler metal and energy and time consumption, joint design must be considered in any type of welding process. This will depend upon several factors including material type, thickness, joint configuration, and strength required. V-groove welds are often made on butt joint for parts with more than $6 \mathrm{~mm}$ of thickness. A butt joint occurs when the surfaces of the members to be welded are in the same plane with their edges meeting and the groove angle (joint chamfer angle) is the included total angle of the joint. The groove angle for a groove weld must be large enough for the torch to fit into the groove and full penetrated weld will be produced. The groove angle depends upon metal thickness, desired electrode extension, and torch nozzle size. Usually, V-groove welds are made for the metals with low weld-ability characteristic, such as API-X42 steel alloy [20].

The weld penetration, bead geometry, and quality of weld are affected by further key variables such as polarity of power supply, electrode orientation (direction of travel), and shielding gas flow. External shielding gases vary in composition and flow rate, allowing the proper arc voltage and amperage parameters to be used. Shielding gas composition also affects bead appearance, fusion, and property of joint. Mixing argon and $\mathrm{CO}_{2}$ as shield gas provides a broad weld with a flat crown and good color match, reduced porosity, and excellent alloy retention with good corrosion resistance. This mixture can also be used for the automatic welding of stainless steel. Argon with controlled addition of $\mathrm{CO}_{2}$ will produce an excellent weld bead appearance with minimum spatter. In this study, shield gas is made of $75 \% \mathrm{Ar}+25 \% \mathrm{CO}_{2}$ mixture with the flow rate of $12 \mathrm{~L} / \mathrm{min}$. Another way to affect the weld shape is to change the direction of travel (electrode orientation). Direction of travel for electrode refers to the GMAW gun position during welding process in relation to the work. The forehand technique, also referred to as a push technique, produces a flatter weld; the weld torch/gun is pointed in the direction of travel. This technique is suitable for thinner sheet metals or when the edges of parts are prepared before welding via machining. Forehand technique is preferred for spray transfer or short-circuits transfer, because it lends itself to better shielding gas coverage over the solidifying weld metal. Forehand technique on sheet materials provides high welding speeds, adequate penetration, and minimal distortion; thus, in this study, this technique is adjusted for all trials. In GMAW process, polarity selection is also a critical factor. Direct Current Electrode Positive (DCEP) is the foremost preferable setup for all industrialists, yielding sufficient localized heating of both filler and base metals. This provides quality bead characteristics and superior weld penetration. On the other hand, Direct Current Electrode Negative (DCEN) produces a globular transfer and poor fusion properties that make its use undesirable; accordingly, DCEP polarity is set out on the welding machine for all experiments [20,21].

Nozzle-to-plate distance $(D)$, arc voltage $(V)$, wire feed rate $(F)$, and welding speed $(S)$ are the most prominent parameters in GMAW process $[1,3,5]$. Similarly, process quality measures include Bead Penetration (BP), Bead Width (BW), Bead Height (BH), and Heat-Affected Zone (HAZ).

Several preliminary tests were conducted to determine the feasible working ranges of each input variable (Table 2). The variable limits were then evaluated by inspecting the weld joint for a smooth appearance and good penetration without any visible defects such as surface porosities and undercut. According to the preliminary test results, the input variables and their corresponding levels are listed in Table 2.

As illustrated, welding speed $(S)$, wire feed rate $(F)$, arc voltage $(V)$, and groove angle $(A)$ would be evaluated at three levels each, while nozzle-work distance $(D)$ is considered at two levels. Other process input factors such as electrode polarity, composition, flow rate of shielding gas, etc. are kept constant.

When the process input parameters and their corresponding ranges are selected, the next step is to select an appropriate design matrix for carrying

Table 2. GMAW process input parameters and their corresponding levels.

\begin{tabular}{cccccc}
\hline Level & $\begin{array}{c}\text { Welding } \\
\text { speed }(\boldsymbol{S}) \\
(\mathbf{c m} / \mathbf{m i n})\end{array}$ & $\begin{array}{c}\text { Wire feed } \\
\text { rate }(\boldsymbol{F}) \\
(\mathbf{m} / \mathbf{m i n})\end{array}$ & $\begin{array}{c}\text { Arc } \\
\text { voltage }(\boldsymbol{V})\end{array}$ & $\begin{array}{c}\text { Groove } \\
\text { Angle }(\boldsymbol{A})\end{array}$ & $\begin{array}{c}\text { Nozzle-work } \\
\text { distance }(\boldsymbol{D})\end{array}$ \\
\hline Level 1 & 15 & 5 & 30 & 50 & 6 \\
Level 2 & 20 & 7 & 35 & 70 & 12 \\
Level 3 & 25 & 9 & 40 & 90 & - \\
\hline
\end{tabular}


out the experiments. Design Of Experiments (DOE) facilitates the identification of the influence of individual parameters, founding the relationships between process parameters and process characteristics, and finally determining the optimum levels. One of the effective techniques that can dramatically reduce the number of experiments required to gather necessary data is Taguchi orthogonal array technique [20,22]. Given the number of input parameters and their levels, in this study, Taguchi's $L_{36}$ has been nominated to provide a design for test runs. To increase accuracy, experimental tests are carried out in random orders.

Bridge Cam (TWI model) was employed for measuring BHs and BWs (Figure 3). Measurements were taken in three places along the weld lines and then averaged out. Two transverse cross sections were made on each sample for measuring HAZs and BPs. Next, the cut faces were polished and etched using $10 \%$ Nital solution to show WBG specifications and heat-affected zones. Then, an optical microscope with X10 magnification was used (Figure 3). Afterwards, the images were processed by Microstructural Image Processing (MIP) software to determine HAZs and WBGs of samples.

A sample of weld joint with transverse cross section processed by MIP software is illustrated in Figure 4.

Parameters, set along with their corresponding outputs, are illustrated in Table 3; besides the test numbers, the first five columns represent input parameters settings used to perform experiments and the measured process outputs have been shown in the last 4 columns.

\subsection{Analysis of variance of process characteristics}

The basic idea behind analysis of variance (ANOVA) is to determine how well a model fits the experimental data and, therefore, represents the actual process under study [22-24]. ANOVA results may provide the percent contributions of each parameter. The percent contributions of the GMAW parameters on BP, BW, $\mathrm{BH}$, and HAZ are shown in Figures 5, 6, 7, and 8, respectively [22].

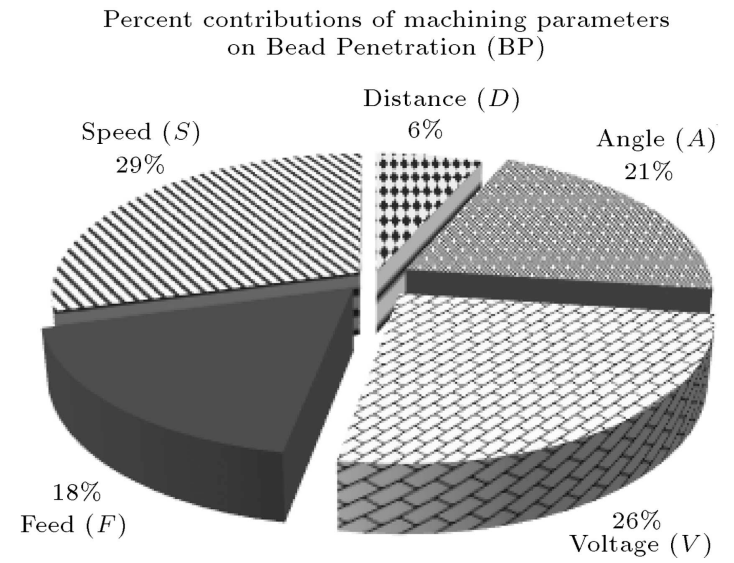

Figure 5. Percent contributions of machining parameters to the BP.
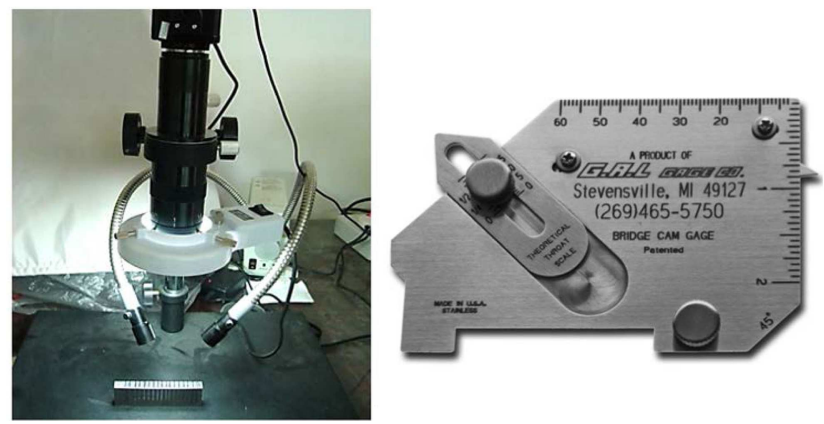

Figure 3. Bridge cam welding gauge and optical microscope used for measuring process quality measures.
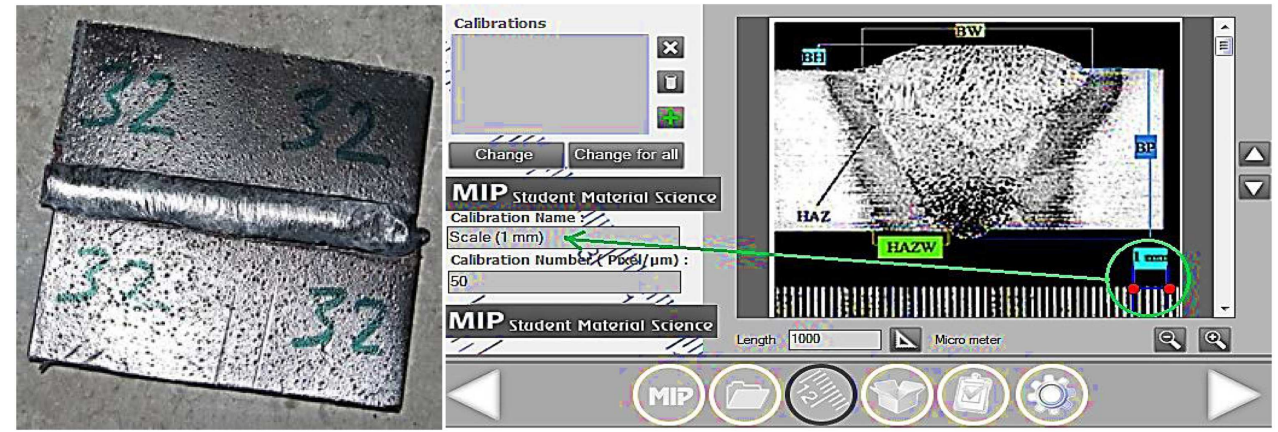

Figure 4. MIP software used for evaluation of WBG and HAZ . 
Table 3. Taguchi design of experiments for GMAW process and their corresponding experimental outputs.

\begin{tabular}{|c|c|c|c|c|c|c|c|c|c|}
\hline No. & $\begin{array}{c}D \\
(\mathrm{~mm})\end{array}$ & $\begin{array}{c}A \\
\text { (degree) }\end{array}$ & $\begin{array}{c}V \\
(\mathrm{v})\end{array}$ & $\begin{array}{c}F \\
(\mathrm{~m} / \min )\end{array}$ & $\begin{array}{c}S \\
(\mathrm{~cm} / \mathrm{min})\end{array}$ & $\begin{array}{c}\text { BW } \\
(\mathrm{mm})\end{array}$ & $\begin{array}{c}\text { BP } \\
(\mathrm{mm})\end{array}$ & $\begin{array}{c}\text { BH } \\
(\mathbf{m m})\end{array}$ & $\begin{array}{l}\text { HAZ } \\
(\mathrm{mm})\end{array}$ \\
\hline 1 & 6 & 50 & 30 & 5 & 15 & 8.99 & 5.55 & 2.43 & 3.51 \\
\hline 2 & 6 & 70 & 35 & 7 & 20 & 8.61 & 5.28 & 2.64 & 3.99 \\
\hline 3 & 6 & 90 & 40 & 9 & 25 & 10.33 & 5.14 & 2.85 & 4.25 \\
\hline 4 & 6 & 50 & 30 & 5 & 15 & 8.99 & 5.55 & 2.43 & 3.93 \\
\hline 5 & 6 & 70 & 35 & 7 & 20 & 9.69 & 5.28 & 2.64 & 3.99 \\
\hline 6 & 6 & 90 & 40 & 9 & 25 & 10.03 & 5.14 & 2.85 & 4.33 \\
\hline 7 & 6 & 50 & 30 & 7 & 25 & 7.26 & 4.48 & 2.30 & 3.02 \\
\hline 8 & 6 & 70 & 35 & 9 & 15 & 11.44 & 6.13 & 4.01 & 4.92 \\
\hline 9 & 6 & 90 & 40 & 5 & 20 & 10.80 & 4.71 & 2.21 & 4.17 \\
\hline 10 & 6 & 50 & 30 & 9 & 20 & 8.33 & 5.79 & 3.04 & 3.63 \\
\hline 11 & 6 & 70 & 35 & 5 & 25 & 8.37 & 3.94 & 2.26 & 3.25 \\
\hline 12 & 6 & 90 & 40 & 7 & 15 & 11.03 & 6.6 & 3.10 & 5.26 \\
\hline 13 & 6 & 50 & 35 & 9 & 15 & 10.25 & 6.76 & 4.06 & 4.73 \\
\hline 14 & 6 & 70 & 40 & 5 & 20 & 10.22 & 5.24 & 2.45 & 4.05 \\
\hline 15 & 6 & 90 & 30 & 7 & 25 & 8.26 & 3.50 & 1.84 & 3.25 \\
\hline 16 & 6 & 50 & 35 & 9 & 20 & 9.25 & 5.74 & 3.54 & 4.09 \\
\hline 17 & 6 & 70 & 40 & 5 & 25 & 9.16 & 4.49 & 2.21 & 3.62 \\
\hline 18 & 6 & 90 & 30 & 7 & 15 & 10.62 & 4.98 & 2.33 & 4.22 \\
\hline 19 & 12 & 50 & 35 & 5 & 25 & 8.50 & 4.81 & 2.54 & 2.98 \\
\hline 20 & 12 & 70 & 40 & 7 & 15 & 13.37 & 6.70 & 3.77 & 4.88 \\
\hline 21 & 12 & 90 & 30 & 9 & 20 & 10.37 & 4.14 & 2.60 & 3.72 \\
\hline 22 & 12 & 50 & 35 & 7 & 25 & 8.83 & 4.76 & 3.00 & 3.26 \\
\hline 23 & 12 & 70 & 40 & 9 & 15 & 13.74 & 6.43 & 4.40 & 5.21 \\
\hline 24 & 12 & 90 & 30 & 5 & 20 & 9.72 & 3.25 & 1.82 & 3.63 \\
\hline 25 & 12 & 50 & 40 & 7 & 15 & 12.41 & 6.82 & 5.35 & 5.49 \\
\hline 26 & 12 & 70 & 30 & 9 & 20 & 9.81 & 4.60 & 2.89 & 2.59 \\
\hline 27 & 12 & 90 & 35 & 5 & 25 & 9.68 & 3.24 & 1.91 & 3.20 \\
\hline 28 & 12 & 50 & 40 & 7 & 20 & 10.78 & 6.33 & 3.80 & 4.06 \\
\hline 29 & 12 & 70 & 30 & 9 & 25 & 8.80 & 3.94 & 2.51 & 3.22 \\
\hline 30 & 12 & 90 & 35 & 5 & 15 & 12.43 & 4.61 & 1.93 & 4.16 \\
\hline 31 & 12 & 50 & 40 & 9 & 25 & 9.94 & 6.02 & 3.99 & 3.87 \\
\hline 32 & 12 & 70 & 30 & 5 & 15 & 9.72 & 4.40 & 2.31 & 3.57 \\
\hline 33 & 12 & 90 & 35 & 7 & 20 & 11.20 & 4.34 & 2.60 & 3.93 \\
\hline 34 & 12 & 50 & 40 & 5 & 20 & 10.39 & 5.51 & 3.09 & 3.71 \\
\hline 35 & 12 & 70 & 30 & 7 & 25 & 8.56 & 3.55 & 2.23 & 3.00 \\
\hline 36 & 12 & 90 & 35 & 9 & 15 & 11.29 & 6.07 & 3.47 & 5.73 \\
\hline
\end{tabular}

According to Figure 5, welding speed is the major factor affecting the BP with $29 \%$ contribution, followed by arc voltage and angle with $26 \%$ and $21 \%$, respectively. Moreover, it reveals that nozzle-to-plate distance has trivial effect on BP.

Furthermore, welding speed is the major factor affecting the BW (Figure 6) with 31\% contribution, followed by arc voltage with $27 \%$ effect. Figure 6 depicts that nozzle-to-plate distance has the least significance with $11 \%$ contribution.

The main process parameter affecting $\mathrm{BH}$ is arc wire feed rate with $27 \%$ contribution (Figure 7 ). According to this figure, welding speed and groove angle are the next significant parameters affecting the BP with $24 \%$ and $21 \%$ contributions, respectively.

Figure 8 illustrates the percentage contributions 


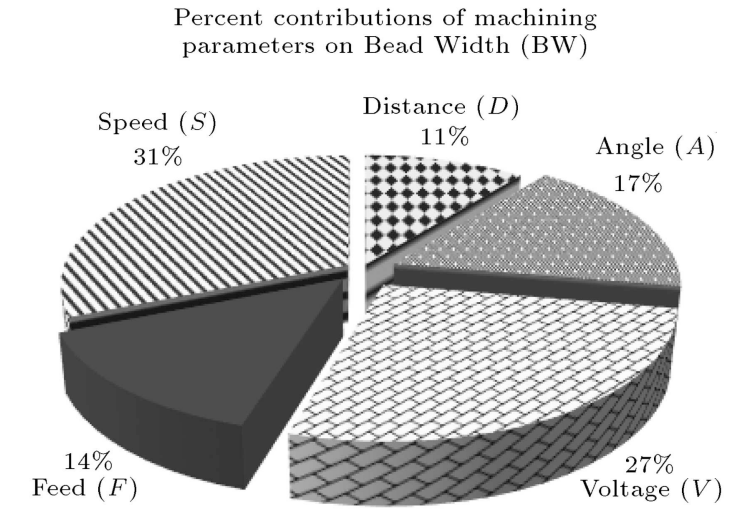

Figure 6. Percent contributions of machining parameters to the BW.

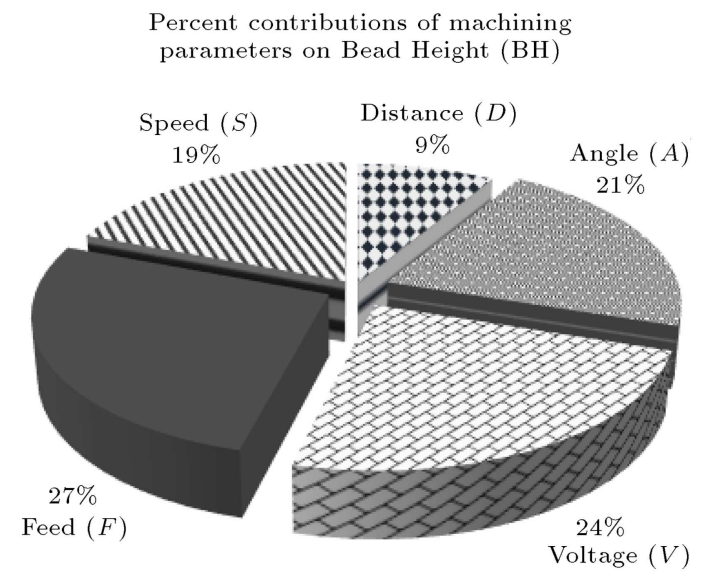

Figure 7. Percent contributions of machining parameters to the $\mathrm{BH}$.

Percent contributions of machining parameters on Heat Affected Zone (HAZ)

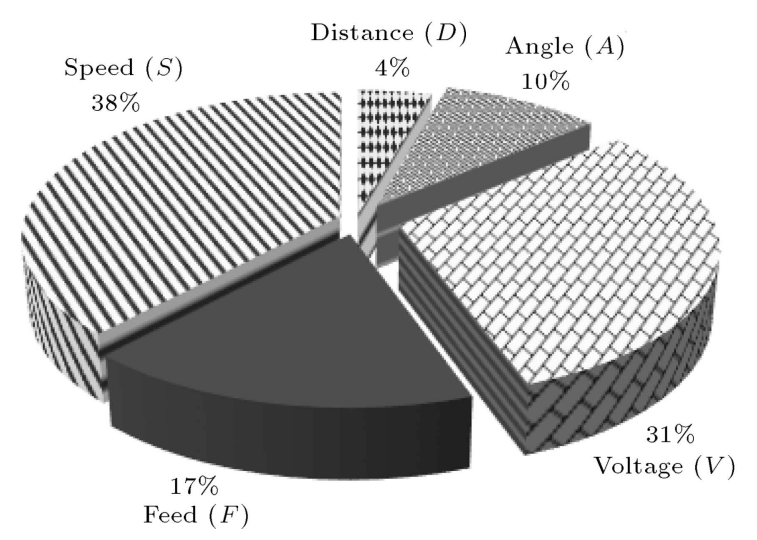

Figure 8. Percent contributions of machining parameters to the HAZ.

of process parameters on the HAZ. According to this figure, the most important parameter that affects the HAZ is welding speed with $38 \%$ contribution followed by arc voltage and wire feed rate with $31 \%$ and $17 \%$ contributions, respectively. Nozzle to plate distance has the least effect on the HAZ with $4 \%$ contribution.
In the following sections, these measured process outputs are used to model the GMAW using BPNN.

\section{Back propagation neural network model for GMAW process}

Back Propagation Neural Network (BPNN) is the improvement of Artificial Neural Network (ANN) algorithm learning representations by back-propagating errors, which was developed in 1985 by Rumelhart et al. [25] and has been widely used in parameters optimization in many fields such as electric discharge machining process, plastic injection molding, blending polyethylene terephthalate with titanium dioxide particles, even medicine, etc. [25]. ANNs are built by connecting processing units, called nodes or neurons. Each input $\left(X_{i}\right)$ is associated with some weight $\left(W_{i}\right)$, which takes a portion of the input to the node for processing. The node combines the inputs $\left(X_{i} W_{i}\right)$ and produces net input, which in turn is transformed into output with the help of transfer/activation function [21]. Learning, generalization and parallel processing are important advantages of ANN that make it suitable for GMAW process modeling [21].

\subsection{BPNN network developing}

Multi-Layer Perceptron (MLP) is one of the most commonly used ANN structures because of its capability to solve non-linearly separable classification problems and to approximate continuous functions [16,25]. A supervised way in the training stage has been used for tuning of its weights and biases, providing a set of pairs of input-output values, which allow the MLP to learn the relations between the input and output variables [25].

A BPNN consists of multiple layers of nodes in a directed scheme, with each layer being fully connected to the next one. Except for the input nodes, each node is a neuron with a nonlinear activation function defined by [25]:

$$
F_{i, j}=\frac{1}{1+\exp ^{-P\left(W_{i, j-1}, O_{i, j-1}\right)}},
$$

where, for the $i$ th neuron in the $j$ th layer, $P\left(W_{i, j-1}, O_{i, j-1}\right)$ is given by:

$$
P\left(W_{i, j-1}, O_{i, j-1}\right)=\sum_{j=1}^{m} \sum_{i=1}^{n} W_{i, j-1} . O_{i, j-1},
$$

where, $n$ and $m$ are the numbers of hidden layers and neurons in each layer, respectively. $W_{i, j-1}$ is the weight of the $i$ th neuron in the $(j-1)$ th layer. In this study, for modeling of the GMAW process, the total number of input nodes is five (nozzle-to-plate distance, groove angle, arc voltage, wire feed rate, and welding speed). The best architecture for modeling 
(the number of hidden layers and the number of nodes in each hidden layer) has been chosen by trial and error method. Furthermore, the transfer function of each processing element is identified and the next network is trained to interrelate the process parameters to output responses. The outputs of trained model are $\mathrm{BW}, \mathrm{BP}$, $\mathrm{BH}$, and HAZ.

Since the number of outputs for the trained model is four: BP, BW, BH and HAZ, linear transfer functions have dealt with outputs of nodes in the last hidden layer to calculate the network outcomes $\left(y_{k}^{(\text {net })}\right)$ as:

$$
\begin{gathered}
y_{k}^{(\text {net })}=c_{i k} \times P\left(W_{i, j-1}, O_{i, j-1}\right)+b_{i k}, \\
k=1-4,
\end{gathered}
$$

where, $c_{i k}$ and $b_{i k}$ are constant real numbers $\left(b_{i k}=\right.$ biases). Network training involves two phases through different layers of the network: a forward phase and a backward phase. In the forward phase, input vectors are presented and propagated forward to compute the outputs and the Mean Square Error (MSE) via the following relation:

$$
\mathrm{MSE}=\frac{1}{n} \sum_{k=1}^{n}\left(Y_{k}-y_{k}^{(\text {net })}\right)^{2}
$$

The backward phase is an iterative error reduction performed in the backward direction from the output layer to the input layer. The Levenburg-Marquest algorithm is used to minimize the MSE [20,25]. Several tests are carried out to find the best neural network architecture, training parameters, and learning algorithm coefficients. Appropriate BPNN architecture with three hidden layers is selected. A 5-5-3-6-4 architecture results in the best interpolation performance and less MSE value. Configuration of the developed BPNN is schematically illustrated in Figure 9.

The comparison between the capabilities of response predictions by the developed model and the experiments has been shown in Figure 10. Good

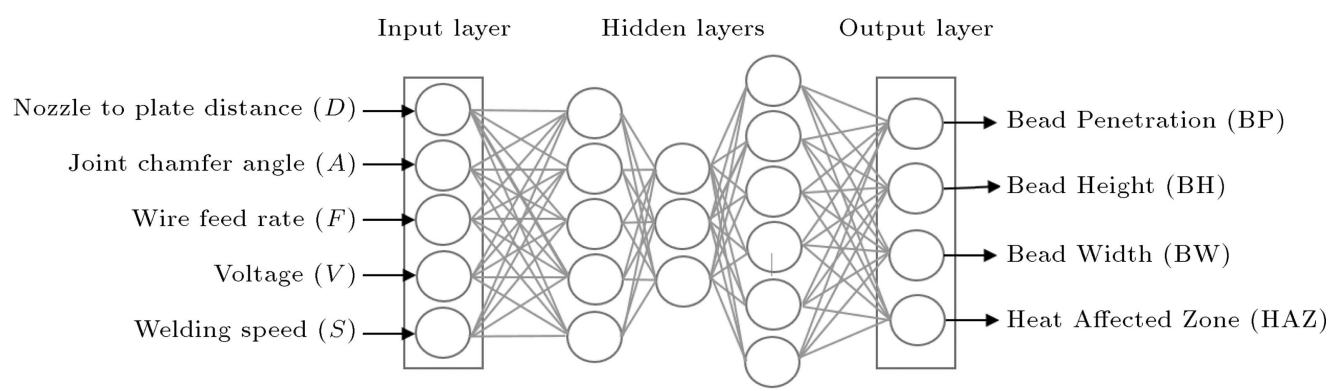

Figure 9. Architecture of back propagation neutral network model for GMAW process.
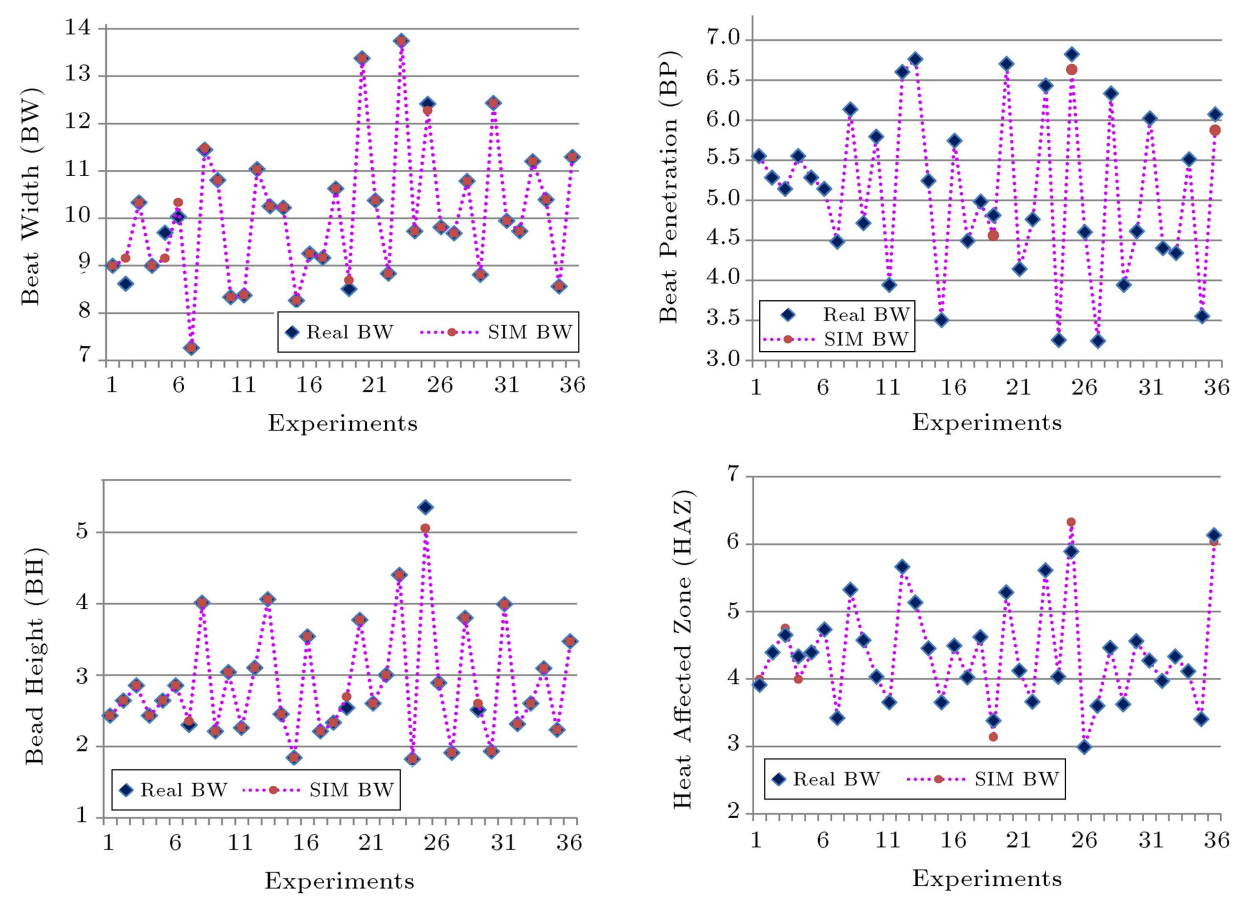

Figure 10. Comparison between experimental and predicted BWs, BPs, BHs, and HAZs by the BPNN models. 
agreement with a negligible small error exists; thus, the developed BPNN predicts the process in a favorable level.

As clearly proved in Figure 10, the predicted outputs given by BPNN closely follow the experimentally measured data. The relative errors between predicted and measured BWs, BPs, BHs, and HAZs are $0.52 \%$, $0.33 \%, 0.43 \%$, and $0.82 \%$, respectively. Maximum error is less than $6 \%$ for all 36 data sets. Consequently, the developed BPNN model may appropriately substitute the actual GMAW process. In the following, this model has been used as the process estimator in the proposed BPNN-PSO optimization process to find the optimal parameters settings.

Concerning the statistically significant parameters (not involved in this paper), it is clarified that within the parameters selected for the research, welding speed $(S)$ and arc voltage $(V)$ are the major factors affecting all output objectives. When the traveling speed increases, the focus of arc energy on the molten zone decreases and results in a narrower and lower penetrated weld bead. On the other hand, when the arc energy input focus in specific area of the plate decreases, the HAZ and thermal effect on base metal decrease too [2]. Fast torch traveling has negative influence on the process performance and results in improper weld joint. Low
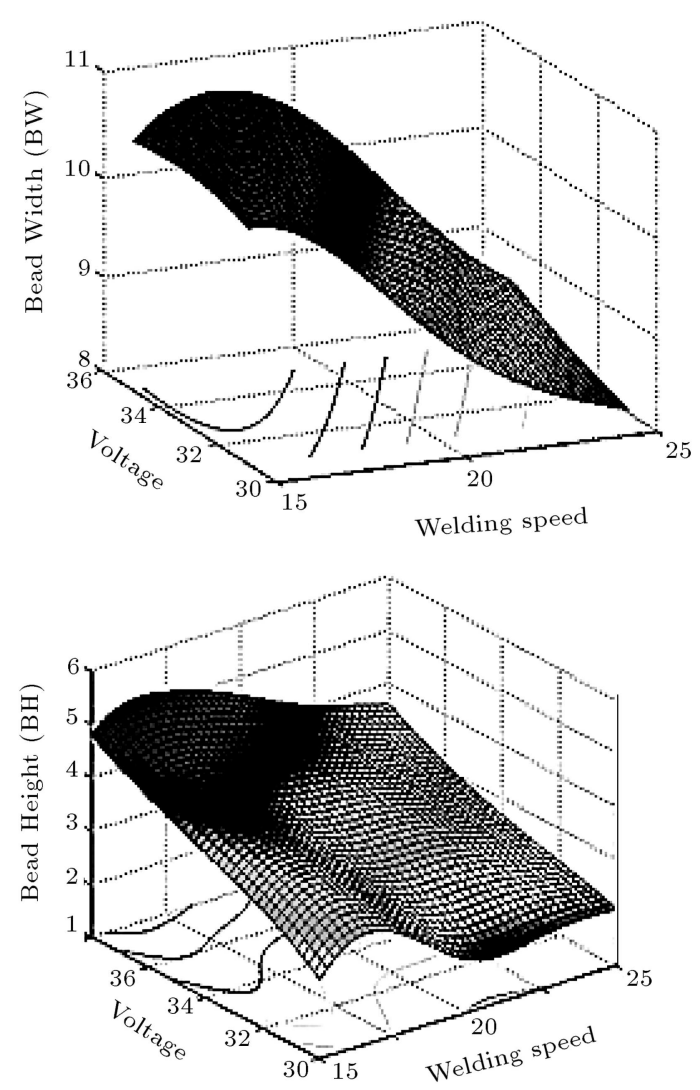

Figure 11. 3D surface plot of the predicted responses speed selection increases the operation time and reduces the productivity; therefore, favorable welding speed is expected to be obtained. As arc voltage and the wire feed rate increase, all of the process responses increase. The increase in arc voltage increases the arc energy and hence, the heat input in plates increases. However, by increase in welding speed, the required energy for melting the wire electrode should be increased; but, this energy is not focused on the joint fusion sufficiently; hence, an optimum selection of voltage and welding speed is expected.

The direct effect of these two main influencing parameters on the process performance measures was studied via 3D response surfaces by keeping the rest of the process parameters at the constant levels. The graph given in Figure 11 shows the predicted output performance measures depending on the welding speed and voltage. They demonstrate the interaction effect of welding speed and voltage on the measured responses. Other processing input parameters are maintained constant: $D=6 \mathrm{~mm}, F=7 \mathrm{~m} / \mathrm{min}$, and $A=70^{\circ}$.

It is ascertained from Figure 11 that weld penetration, width of heat-affected zone, bead height, and bead width attain their maximum values when speed of welding is in the lowest level while voltage is in the highest level.
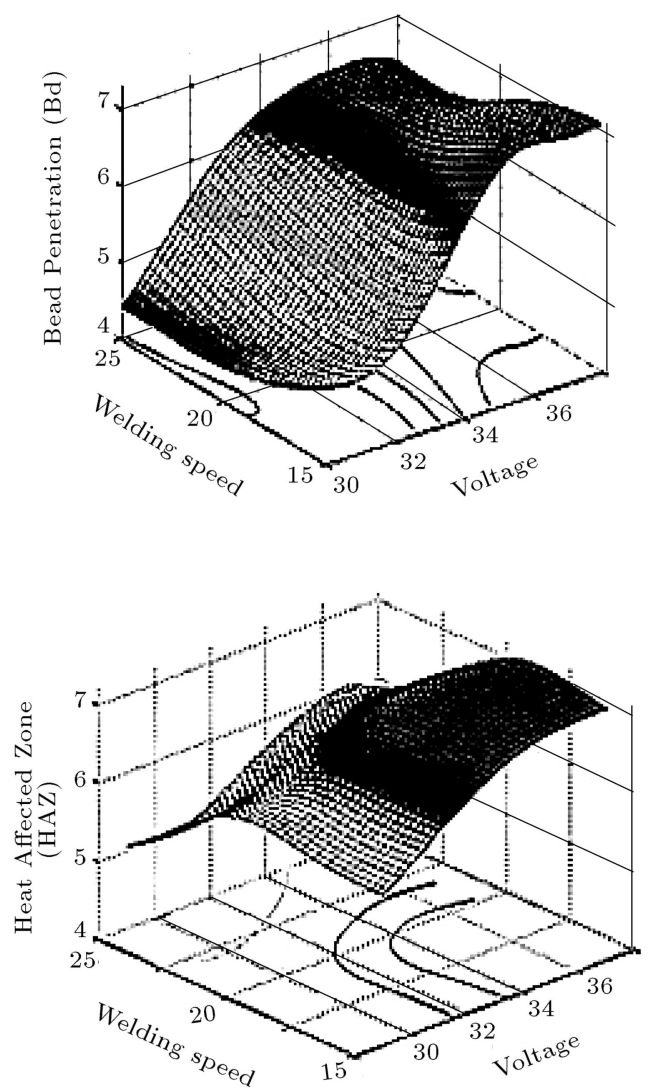

(BW, BP, BH and HAZ) versus voltage and welding speed. 


\section{Optimization of GMAW process}

\subsection{Problem explanation}

Looking for the best design by different variables, which satisfies the best process performance while not disturbing the design restraints, is the goal of process optimization. A proper weld shall be such that the completed weld has a substantially uniform cross section. At no point shall the crown surface of bead be below the outside surface of the parent plate, nor should it be raised above the parent by more than an upper limit value. Also, the bead width should be a little bigger than the original groove (crown width). On the other hand, the optimum value of bead penetration is equal to thickness of sample plates, while greater penetration requires larger heat inputs; thus, the risk of undercut, high overlap, and heat-caused defects in parent material increases.

A standard weld pool is defined in American Petroleum Institute (user manual no 1104 released by the API) by its appearance (Figure 12) [21].

Therefore, based on API standard [21], the following rules may be used to achieve a high quality WBG:

$\mathrm{OGW}<\mathrm{BW}<\mathrm{OGW}+1.6 \mathrm{~mm}$,

$$
\mathrm{BP} \geq 6 \mathrm{~mm}, \quad 0.8 \mathrm{~mm}<\mathrm{BH}<1.6 \mathrm{~mm} .
$$

Settings of GMAW parameters can significantly influence the WBG specifications. Furthermore, Original Groove Width (OGW) of the parameter is directly related to the Root Opening $\left(R_{O}\right)$, Root Length $\left(R_{L}\right)$, groove angle $(A)$, and workpiece thickness $(T)$ (Figure 13). It is given by:

$$
\mathrm{OGW}=2 \times\left(T-R_{L}\right) \times \operatorname{tg}\left(\frac{A}{2}\right)+R_{o} .
$$

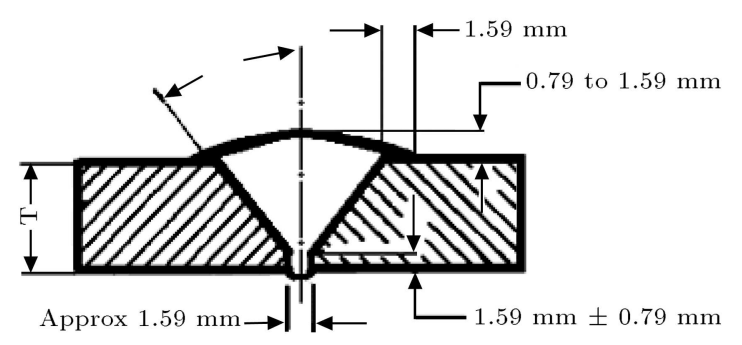

Figure 12. Desired V-beveled butt joint for gas pipeline [21].

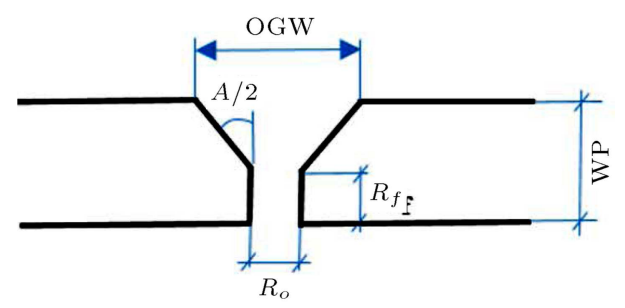

Figure 13. Specifications of joint edge geometry in GMAW process.

\subsection{Particle swarm optimization algorithm}

Particle Swarm Optimization (PSO) algorithm is an intelligence technique developed by Eberhart and Kennedy in 1995 [18]. PSO is a stochastic and population-based adaptive optimization method inspired by social behavior of bird flocks. As one of the versatile and efficient swarm intelligence techniques, PSO has attracted increasing attention and been widely applied in various areas [26-29]. The outstanding feature of PSO is its new solution generation mechanism, which distinguishes it from other biologically inspired optimization techniques. PSO guides its search direction by this generation strategy in which each particle updates its velocity through a linear combination of its present status, best historical experience, and the best swarm experience. Such a velocity updating strategy is easy to achieve, but experimentally inefficient when searching in a complex space. The reason may be that the swarm will converge quickly by tracking only its best historical experience and best global experience. It is easy to fall into local optima due to the lack of an effective escaping mechanism at the latter stage of evolution. Therefore, how to choose the typical and promising representative solutions among the current population and powerful local search techniques to execute the local optima on these promising solutions is effective on the performance of PSO [26,28]. Although conventional PSO can rapidly find out good solutions, it may be trapped in local minimum and fail to converge to the best position [17]. To obviate this problem and improve resolving capacity, an improved PSO algorithm with mutation is used. Using both the best and the worst particle positions in the improved PSO algorithm accelerates finding of the optimal solution. Particle positioning is accomplished by modifying the particle parameters, including speed and position $\left(V_{i}\right.$ and $\left.X_{i}\right)$, defined by the following expressions [27].

$$
\begin{aligned}
X_{i}(k+1)= & X_{i}(k)+V_{i}(k+1), \\
V_{i}(k+1)= & \gamma \cdot V_{i}(k)+c_{1} r_{1}\left(p_{i}-x_{i}(k)\right) \\
& +c_{2} r_{2}\left(p_{g}-x_{i}(k)\right),
\end{aligned}
$$

where $c_{1}$ and $c_{2}$ are acceleration parameters, $r_{1}$ and $r_{2}$ are random numbers ranging between 0 and 1 , and $\gamma$ represents the inertia weight, which decreases linearly from 1 to near 0 as the search progresses. In addition, $p_{i}$ and $p_{g}$ denote the best position of the $i$ th bird and the best position of the entire colony, respectively. Each heuristic algorithm has its own parameters that affect its performance in terms of solution quality and computational speed. It is noted that the parameters of PSO also have to be tuned to achieve the best performance. Flowchart of the proposed BPNN-PSO 


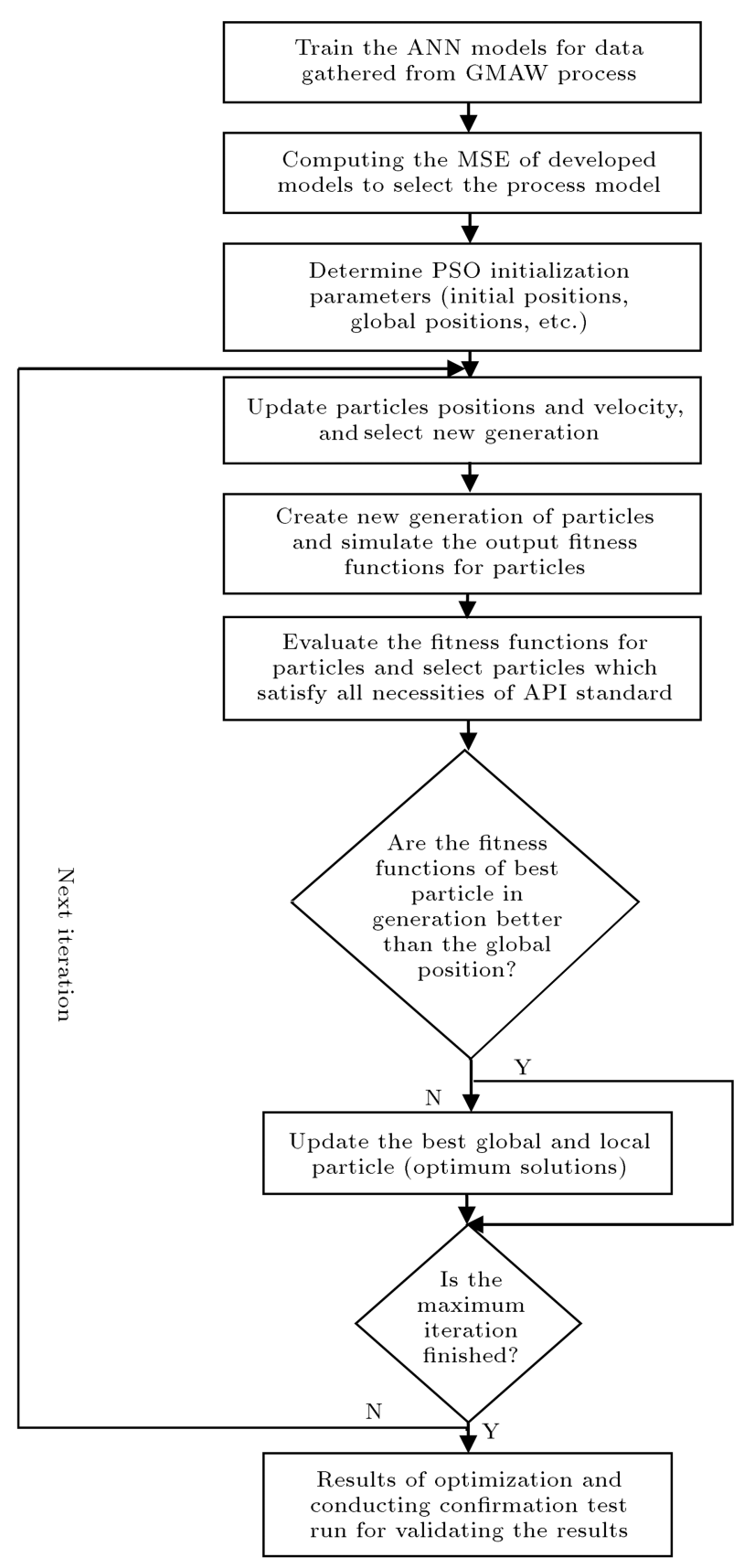

Figure 14. Flowchart of the proposed BPNN-PSO algorithm for GMAW process optimization.

algorithm for GMAW process optimization is shown in Figure 14.

\subsection{Results of optimization and verification tests}

In order to obtain a weld joint with desired WBG specifications and minimum HAZ on API-X42 steel plates, an integrated multi-criteria BPNN-PSO procedure has been employed. To define the ideal dimensions of WBG based on API standard, Eq. (5) is used [19]. According to Table 2, groove angle of plates can differ between 50 to 90 degrees $\left(50^{\circ}<A_{i}<90^{\circ}\right)$, arc voltage may change

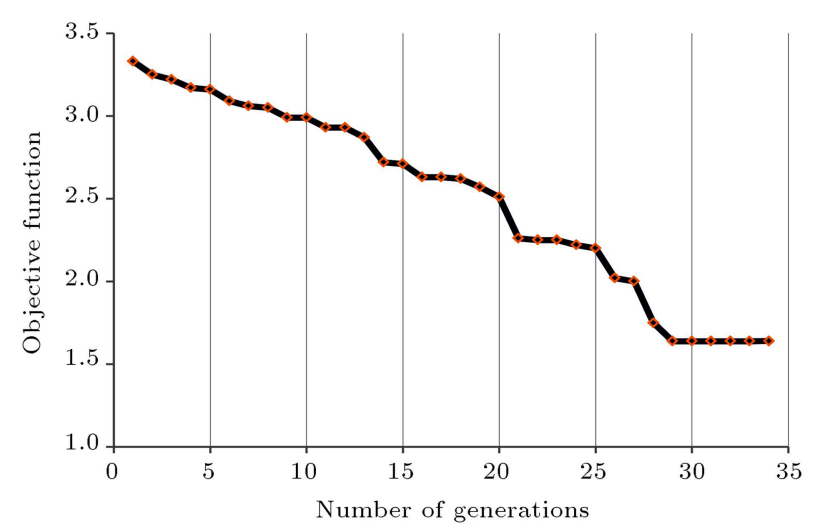

Figure 15. Convergence curve for the proposed algorithm.

in the range of 30 to 40 volts $\left(30<V_{i}<40\right)$, etc. The BPNN model, incorporated into PSO algorithm in each iteration, acts as the objective function to calculate the GMAW characteristics. For the best set of values for parameters, by which HAZ is minimized and predefined dimensions of WBG are obtained, the feasible solution space is searched by the algorithm.

As stated, to develop the performance of the optimization algorithm, the values of its parameters must be properly determined. Inertia weight was set at 0.5 and the best population size was found to be 20 for all generations based on the results of several test runs. The computer code of BPNN-PSO algorithm was run several times using a set of various initial populations in order to avoid local optima. After a pre-determined number of non-improving generations was observed, the algorithm terminated. Figure 15 exhibits the convergence curve of a sample run in which the code terminated after 35 generations, including 5 consecutive generations with no improvement in the objective function.

Table 4 shows two sets of the best GMAW process parameters settings for which the value of the multicriteria objective function is minimized. It should be stated that both sets ended in the same values for the objective function. In Table 4, optimal process parameters given by PSO algorithm have been shown in the first 5 columns. Experiments were carried out based on the optimized settings, whose measured outputs are reported in the last 4 columns of the table to assess the performance of the proposed BPNN-PSO method. It has been shown that optimized HAZs are at least $75 \%$ smaller than all those reported in Table 4 (1.64 and $1.69 \mathrm{~mm}$ vs. $3.00 \mathrm{~mm}$ in test no. 35) by comparing GMAW process test results. Moreover, the measured weld beads are well within the proper ranges delineated by API standard (Eq. (5)). Likewise, the WBGs resulted from optimized parameters settings are much better than all those of the 36 tests performed based on Taguchi method. These results approve that the proposed approach is quite efficient in finding 
Table 4. Optimal parameters and their corresponding responses.

\begin{tabular}{|c|c|c|c|c|c|c|c|c|c|}
\hline \multirow{2}{*}{$\begin{array}{l}\text { Optimal } \\
\text { process } \\
\text { setup }\end{array}$} & \multicolumn{5}{|c|}{ Process parameters } & \multicolumn{4}{|c|}{ Experimental responses } \\
\hline & $\begin{array}{c}D \\
(\mathrm{~mm})\end{array}$ & $\begin{array}{c}A \\
\text { (degree) }\end{array}$ & $\begin{array}{c}V \\
(\mathrm{v})\end{array}$ & $\begin{array}{c}F \\
(\mathrm{~m} / \mathrm{min})\end{array}$ & $\begin{array}{c}S \\
(\mathrm{~cm} / \mathrm{min})\end{array}$ & BW & BP & BH & HAZ \\
\hline Setting 1 & 6 & 70 & 33 & 6 & 21 & 6.91 & 6.10 & 1.23 & 1.64 \\
\hline Setting 2 & 7 & 75 & 34 & 6.2 & 20 & 6.96 & 6.12 & 1.49 & 1.69 \\
\hline
\end{tabular}

the best set of parameters settings for multi-criteria optimization of GMAW process.

Large HAZs may cause fracture and corrosion due to pronounced metallurgical changes in this region [29]. Conversely, for higher strength, bigger WBG (especially larger BW and BP) is desired. A satisfactory WBG is often defined by the specific requests and industries for which the welded parts are intended. In most cases, WBG and HAZ are conflicting characteristics in which pre-defined WBGs and small HAZs are to be obtained. Achieving such conflicting objectives necessitates careful selection of parameters settings. Given the vast number of possible combinations for parameters settings, trial and error is quite inefficient. Conversely, multi-criteria modeling and optimization proved to be both more efficient and more effective in finding the best set of GMAW process parameters. With respect to the two characteristics used in this research, optimal parameters settings should produce a weld joint with small HAZ and WBG characteristics close to those given by Eq. (4). Table 4 listed the optimized values of parameters, which indicated that for minimum possible HAZ, both nozzle to plate distance $(D)$ and arc voltage $(V)$ should be at their lower permissible ranges. These, together with the values of other optimized process parameters, ensure that the pre-defined WBG is obtained. Consequently, a well-balanced welded joint may be achieved satisfying both distinct objectives by application of the proposed BPNN-PSO approach.

\section{Conclusion}

Selection of process parameters levels could significantly affect the quality of final product in GMAW process. In contrast, the conflicting nature of the process characteristics and the interactions of process parameters require simultaneous selection of process parameters in order to achieve the conflicting goals. In this study, the effects of GMAW process parameters settings on the 4 important output characteristics for API X42 steel alloy have been investigated. Furthermore, the problem of multi-criteria modeling of the process has been addressed. First, using orthogonal array Taguchi method, a set of experiments has been performed to collect the required data. Then, 5 process input variables, namely, Angle $(A)$, nozzle-to-plate distance $(D)$, welding voltage $(V)$, wire feed rate $(F)$, and welding speed $(S)$, are taken into account using the BPNN model to simultaneously predict 4 outputs responses, namely, Bead Penetration (BP), Bead Width (BW), Bead Height $(\mathrm{BH})$, and HeatAffected Zone (HAZ). The accuracy of the proposed model has been verified using a set of experiments, which illustrate that the proposed model can accurately simulate the actual GMAW process. Next, the model has been coupled with PSO algorithm to optimize the process. The optimization procedure includes finding a certain combination of process parameters to obtain a WBG with specific dimensions and minimize HAZ. According to the results of ANOVA, welding speed is the major factor affecting the BP and BW with $29 \%$ and $31 \%$ contributions, respectively. Moreover, wire feed rate with $27 \%$ and welding speed with $38 \%$ contributions are the most significant parameters affecting $\mathrm{BH}$ and $\mathrm{HAZ}$, respectively. High arc voltage $(V)$ and nozzle to plate distance $(D)$ usually end in larger heat input rate, which increases the size of HAZ. According to the values of optimized parameters given by the proposed procedure, both arc voltage and nozzle to plate distance should be set at their lower levels (6 $\mathrm{m} / \mathrm{min}$ and $33 \mathrm{~V}$, respectively). Such settings, along with the values for other three parameters, would result in a WBG with desired conditions while keeping HAZ on its minimum. The results illustrate that WBGs are well within the desired ranges while HAZs have been reduced considerably, creating a near perfect balance among the conflicting objectives. Furthermore, optimization results are consistent with the inherent characteristics of GMAW process. Moreover, in this study, both performance measures are given equal weights of $50 \%$ each. Any other combination of these two objectives may also be achieved based on the relative importance of the $\mathrm{HAZ}$ and $\mathrm{WBG}$ and with minor modifications in the objective function.

\section{References}

1. Krishnan, S., Kulkarni, D.V. and De, A. "Pulsed current gas metal arc welding of P91 steels using metal cored wires", Journal of Materials Processing Technology, 229, pp. 826-833 (2016).

2. Wang, Z. "A laser back-lighting based metal transfer monitoring system for robotic gas metal arc welding", 
Robotics and Computer-Integrated Manufacturing, $\mathbf{3 8}$, pp. 52-66 (2016).

3. Benyounis, K.Y. and Olabi, A.G. "Optimization of different welding processes using statistical and numerical approaches - A reference guide", Advances in Engineering Software, 39, pp. 483-496 (2008).

4. Kanti, K.M. and Rao, P.S. "Prediction of bead geometry in pulsed GMA welding using back propagation neural network", Journal of Materials Processing Technology, 200, pp. 300-305 (2008).

5. Yang, Z. and Debroy, T. "Modeling macro-microstructures of gas metal arc welded HSLA-100 steel", Metallurgical and Materials Transactions B: Physical Metallurgy and Materials Science, 30(3), pp. 483-493 (1999).

6. Kim, S., Son, J.S., Kim, I.G. and Kim, O.S. "A study on relationship between process variables and bead penetration for robotic $\mathrm{CO}_{2}$ arc welding", Journal of Material Processing Technology, 136(3), pp. 139-145 (2003).

7. Ramazani, A., Mukherjee, K., Abdurakhmanov, A., Prahl, U., Schleser, M., Reisgen, U. and Bleck, W. "Micro-macro-characterisation and modelling of mechanical properties of gas metal arc welded (GMAW) DP600 steel", Materials Science and Engineering: A., 589, pp. 1-14 (2014).

8. Tian, L., Luo, Y., Wang, Y. and Wu, X. "Prediction of transverse and angular distortions of gas tungsten arc bead-on-plate welding using artificial neural network", Materials \& Design, 54, pp. 458-472 (2014).

9. Singh, R.P., Garg, R.K. and Shukla, D.K. " Mathematical modeling of effect of polarity on weld bead geometry in submerged arc welding", Journal of Manufacturing Processes, 21, pp. 14-22 (2016).

10. Kim, I.S., Son, J.S., Lee, S.H. and Yarlagadda, P.K.D.V. "Optimal design of neural networks for control in robotic arc welding", Robotics and ComputerIntegrated Manufacturing, 20, pp. 57-63 (2004).

11. Malviya, R. and Pratihar, D.K. "Tuning of neural networks using particle swarm optimization to model MIG welding process", Swarm and Evolutionary Computation, 1, pp. 223-235 (2011).

12. Nagesh, D.S. and Datta, G.L. "Prediction of weld bead geometry and penetration in shielded metal-arc welding using artificial neural networks", Journal of Materials Processing Technology, 123, pp. 303-312 (2002).

13. Campbell, S.W., Galloway, A.M. and McPherson, N.A. "Artificial neural network prediction of weld geometry performed using GMAW with alternating shielding gases", Welding Journal, 91, pp. 174-181 (2012).
14. Ates, H. "Prediction of gas metal arc welding parameters based on artificial neural networks", Journal of Materials \& Design, 28(7), pp. 2015-2023 (2007).

15. Kolahan, F. and Heidari, M. "A new approach for predicting and optimizing weld bead geometry in GMAW", International Journal of Mechanical Systems Science and Engineering, 2, pp. 138-142 (2010).

16. Nagesh, D.S. and Datta, G.L. "Genetic algorithm for optimization of welding variables for height to width ratio and application of ANN for prediction of bead geometry for TIG welding process", Applied Soft Computing, 10, pp. 897-907 (2010).

17. Dhas, J.E.R. and Kumanan, S. "Optimization of parameters of submerged arc weld using non conventional techniques", Applied Soft Computing, 11, pp. 51985204 (2011).

18. Katherasan, D., Elias, J.V., Sathiya, P. and Haq, A.N. "Simulation and parameter optimization of flux cored arc welding using artificial neural network and particle swarm optimization algorithm", Journal of Intelligent Manufacturing, 25, pp. 67-76 (2014).

19. Dutta, P. and Pratihar, D.K. "Modeling of TIG welding process using conventional regression analysis and neural network-based approaches", Journal of $M a$ terials Processing Technology, 184, pp. 56-68 (2007).

20. Chaki, S., Shanmugarajan, B., Ghosal, S. and Padmanabham, G. "Application of integrated soft computing techniques for optimization of hybrid CO2 laserMIG welding process", Applied Soft Computing, 30, pp. 365-374 (2015).

21. "Welding of pipeline \& related facilities standard", Standard No. 1104, 19th Edn., American Petroleum Institute (API) (2005).

22. Kolahan, F. and Azadi Moghaddam, M. " The use of Taguchi method with grey relational analysis to optimize the EDM process parameters with multiple quality characteristics", Scientia Iranica B, 22(2), pp. 530-538 (2015).

23. Assarzadeh, S. and Ghoreishi, M. "Mathematical modeling and optimization of the Electro-Discharge Machining (EDM) parameters on tungsten carbide composite: Combining response surface methodology and desirability function technique", Scientia Iranica $B$, 22(2), pp. 539-560 (2015).

24. Juang, S.C. and Tarng, Y.S. "Process parameter selection for optimizing the weld pool geometry in the tungsten inert gas welding of stainless steel", Journal of Materials Processing Technology, 122, pp. 33-37 (2002).

25. Firouzi, A. and Rahai, A. "An integrated ANN-GA for reliability based inspection of concrete bridge decks considering extent of corrosion-induced cracks and life cycle costs", Scientia Iranica A, 19(4), pp. 974-981 (2012). 
26. Zhao, X., Lin, W., Hao, J., Zuo, X. and Yuan, J. "Clustering and pattern search for enhancing particle swarm optimization with Euclidean spatial neighborhood search", Neurocomputing, 171, pp. 966-981 (2016).

27. Lee, K.H. and Kim, K.W. "Performance comparison of particle swarm optimization and genetic algorithm for inverse surface radiation problem", International Journal of Heat and Mass Transfer, 88, pp. 330-37 (2015).

28. Norouzi, N., Sadegh-Amalnick, M. and Alinaghian, M. "Measuring and evaluating of the particle swarm optimization in a periodic vehicle routing problem", Measurement, 62, pp. 162-169 (2015).

29. Kong, Z., Jia, W., Zhang, G. and Wang, L. "Normal parameter reduction in soft set based particle swarm optimization algorithm", Applied Mathematical Modeling, 39, pp. 4808-4820 (2015).

\section{Biographies}

Masoud Azadi Moghaddam was born in April 1984, in Mashhad, Iran. He has a BSc degree in Production and Manufacturing Engineering. He has also obtained an MSc degree in Mechanical Engineering (Manufacturing Engineering) from Ferdowsi University of Mashhad, Iran. He is now a PhD candidate in the same university under the supervision of Dr. Kolahan. The research he has undertaken includes modeling and optimization of advanced manufacturing processes. Mr. Azadi has published several journal and conference papers in his field of research during his post graduate studies.

Reza Golmezerji was born in February 1986, in Ghochan, Iran. He has a BSc degree in Production and Manufacturing Engineering. He has also obtained an MSc degree in Mechanical Engineering (Manufacturing Engineering) from Ferdowsi University of Mashhad, Iran. Under the supervision of Dr. Kolahan, he is now a mechanical teacher in Ministry of Education of Iran. Mr. Golmezerji has published several journal and conference papers in his field of research during his post graduate studies.

Farhad Kolahan is an Associate Professor in the Department of Mechanical Engineering at Ferdowsi University of Mashhad, Iran. He was born in September 1965 in Mashhad, Iran. He received his BSc degree in Production and Manufacturing Engineering from Tabriz University, Iran. He then continued his postgraduate studies abroad and graduated with a $\mathrm{PhD}$ degree in Industrial and Manufacturing Engineering from Ottawa University, Canada, in 1999. Dr. Kolahan's research interests include production planning and scheduling, manufacturing processes optimization, and applications of heuristic algorithms in industrial optimization. 